\title{
Green Building between Tradition and Modernity Study Comparative Analysis between Conventional Methods and Updated Styles of Design and Architecture Processors
}

\author{
Elshimy. $\mathrm{H}^{1}$ \\ Samir. $\mathrm{N}^{2}$ \\ Associate Professor, Architectural Engineering Department, Pharos University, Alexandria, Egypt \\ Assistant Lecture, Architectural Engineering Department, Pharos University, Alexandria, Egypt
}

\begin{abstract}
Green house concept appeared from the ancient to the modern age ages and there is a tendency to use a traditional architecture with a pristine ecological environment areas and through sophisticated systems arrived to modern systems of the upgraded systems by Treatment architectural achieve environmental sustainability in recent years, sustainability concept has become the common interest of numerous disciplines. The reason for this popularity is to perform the sustainable development. The Concept of Green Architecture, also known as "sustainable architecture" or "green house," is the theory, science and style of buildings designed and constructed in accordance with environmentally friendly principles. Green house strives to minimize the number of resources consumed in the building's construction, use and operation, as well as curtailing the harm done to the environment through the emission, pollution and waste of its components.
\end{abstract}

To design, construct, operate and maintain buildings energy, water and new materials are utilized as well as amounts of waste causing negative effects to health and environment is generated. In order to limit these effects and design environmentally sound and resource efficient buildings; "green building systems" must be introduced, clarified, understood and practiced.

This paper aims at highlighting these difficult and complex issues of sustainability which encompass the scope of almost every aspect of human life.

Keywords - Greenhouse; sustainable buildings; natural buildings; living architecture; renewable resources-eco-design; eco-friendly architecture; earth-friendly architecture; environmental architecture; natural architecture.

\section{INTRODUCTION}

Sustainability is comprehensive therefore a complex subject. It is of vital importance to all because it deals with the survival of human species and almost every living creature on the planet. Sustainable and eco-friendly architecture is one of the main aims thans for creating a better life have made as the ultimate model for all their activities. For this reason, moving towards a greener architecture is well-thought-out the main goal of the present architecture of our time [1]

At the rate the development needs of this world is using the scarce and limited resources found on the earth, it is becoming obvious that unless there are major changes to Man's thinking and behavior, the future of civilization as known today is dubious. This complex subject has no straight forward solution, especially considering that sustainability is a goal for all to reach as they continually strive to reach towards it. Green architecture produces environmental, social and economic benefits. Environmentally, green architecture helps reduce pollution, conserve natural resources and prevent environmental degradation. Economically, it reduces the amount of money that the building's operators have to spend on water and energy and improves the productivity of those using the facility [2]

And, socially, green buildings are meant to be beautiful and cause only minimal strain on the local infrastructure.

The buildings in which we live, work, and play protect us from nature's extremes, yet they also affect our health and environment in countless ways. As the environmental impact of buildings becomes more 
apparent, a new field called "green building" is gaining momentum. Green, or sustainable, building is the practice of creating and using healthier and more resource-efficient models of construction, renovation, operation, maintenance and demolition [3].

\section{PROPLEM STATEMENT}

There is no clear approach to design the green architecture

\section{2. AIM OF STUDY}

Access to appropriate methodology for Egypt correspond to different levels of design in terms of ecological techniques to advanced one

\section{METHODOLOGY}

In order to achieve the stipulated aim, the study presented in this paper, traces the following steps:

1. General overview on applying "Green Architecture" as A concept of sustainability.

2. Analytical Study to ecological project (Adrar Amlal)

3. Analytical Study to advanced project (Tenth of Ramadan City)

\section{GENERAL OVERVIEW ON APPLYING "GREEN ARCHITECTURE "AS A CONCEPT OF SUSTAINABILITY}

\section{A. Green Architecture}

Green architecture, or green design, is an approach to building that minimizes harmful effects on human health and the environment. The "green" architect or designer attempts to safeguard air, water, and earth by choosing eco-friendly building materials and construction practices [3].

\section{B. Green Architecture and Green Design}

Green architecture defines an understanding of environment-friendly architecture under all classifications, and contains some universal consent [4]; it may have many of these characteristics:

- Ventilation systems designed for efficient heating and cooling

- Energy-efficient lighting and appliances

- Water-saving plumbing fixtures
- Landscapes planned to maximize passive solar energy

- Minimal harm to the natural habitat

- Alternate power sources such as solar power or wind power

- Non-synthetic, non-toxic materials

- Locally-obtained woods and stone

- Responsibly-harvested woods

- Adaptive reuse of older buildings

- Use of recycled architectural salvage

- Efficient use of space

While most green buildings do not have all of these features, the highest goal of green architecture is to be fully sustainable.

Also Known As: Sustainable development, ecodesign, eco-friendly architecture, earth-friendly architecture, environmental architecture, natural architecture [5].

\section{Consideration for Green Building}

Green building involves consideration in four main areas: site development, material selection and minimization, energy efficiency, and indoor air quality

- Consider site development to reduce the impact of development on the natural environment. For example, orient the buildings to take advantage of solar access, shading and wind patterns that will lessen heating and cooling loads.

- Carefully select materials that are durable, contain recycled content, and are locally manufactured to reduce negative environmental impacts. A growing market exists of quality recycled products at affordable prices.

- Incorporate energy-efficient design into buildings to create an efficient and comfortable environment. Take advantage of the natural elements and technologies to conserve resources and increase occupant comfort/productivity while lowering long-term operational costs and pollutants [6].

- Design for high indoor air quality to promote occupant health and productivity. 
- Minimize the waste in construction and demolition processes by recovering materials and reusing or recycling those [7].

\section{THE PRINCIPLES OF GREEN BUILDING DESIGN}

The green building design process begins with an intimate understanding of the site in all its beauties and complexities. An ecological approach to design aims to integrate the systems being introduced with the existing on-site ecological functions performed by Mother Nature.

These ecological functions provide habitat, respond to the movements of the sun, purify the air as well as catch, filter and store water. Designers can create features in their buildings that mimic the functions of particular eco-systems. Species that thrive in natural ecosystems may also utilize habitats created in manmade structures. Creating new habitat on structures in urbanized areas is especially important to support bio-diversity and a healthy ecosystem [2].

The following points summarize key principles, strategies and technologies which are associated with the five major

Elements of green building design which are: Sustainable Site Design; Water Conservation and Quality; Energy and Environment; Indoor Environmental Quality; and Conservation of Materials and Resources. This information supports of the use of the USGBC LEED Green Building Rating System, but focuses on principles and strategies rather than specific solutions or technologies, which are often site specific and will vary from project to project (USGBC).

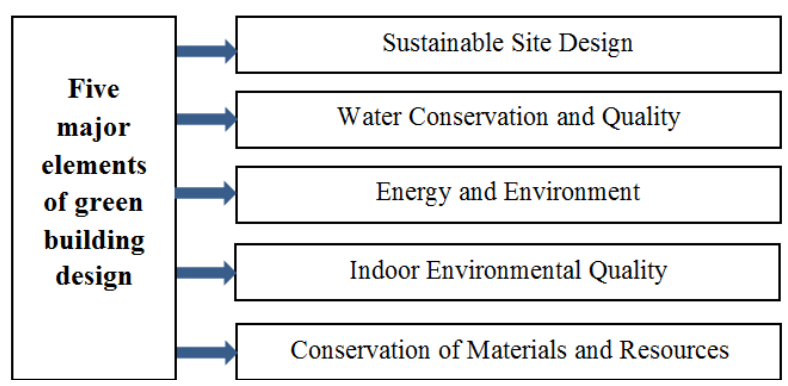

Fig. 1. Elements of green building design by author (USGBC).

\section{E. GREEN BUILDING BENEFITS}

Green building is not a simple development trend; it is an approach to building suited to the demands of its time, whose relevance and importance will only continue to increase (USGBC)

- Comfort. Because a well-designed passive solar home or building is highly energy efficient, it is free of drafts. Extra sunlight from the south windows makes it more cheerful and pleasant in the winter than a conventional house [8].

- Economy. If addressed at the design stage, passive solar construction doesn't have to cost more than conventional construction, and it can save money on fuel bills [9].

- Aesthetics. Passive solar buildings can have a conventional appearance on the outside, and the passive solar features make them bright and pleasant inside.

- Environmentally responsible. Passive solar homes can significantly cut use of heating fuel and electricity used for lighting. If passive cooling strategies are used in the design, summer air conditioning costs can be reduced as well [10].

\section{ANALYTICAL STUDY TO ECOLOGICAL PROJECT (ADRAR AMLAL)}

An applied analytical study on a project of "Adrar Amlal" hotel in "Gaafar oasis"at Siwa in Egypt.

The mechanism of choosing the construction system is considered as an important stage in urban projects due to its relation with a group of limits forming the building technology, the mechanism of choice is related to the engineering method of decision support system used in construction system through building technical analysis and its application limits which passThrough a group of consecutive stages related to the project nature and the surrounding environment especially in the distinguished sites environmentally to assure the environmental resource conservation for humanity secure in his environment which needs from him to know the Ecological dimensions (capacity-dependence-recycling).

The research aims to achieve a group of goals, the most important of them is to reach a mechanism to choose the suitable construction system matching 
with sustainable development forming harmony between the design and the construction system and the sustainable development to reach the best economic efficiency of the project encouraging the environment sustainability as one of affecting sustains for a balanced environmental urbanism.

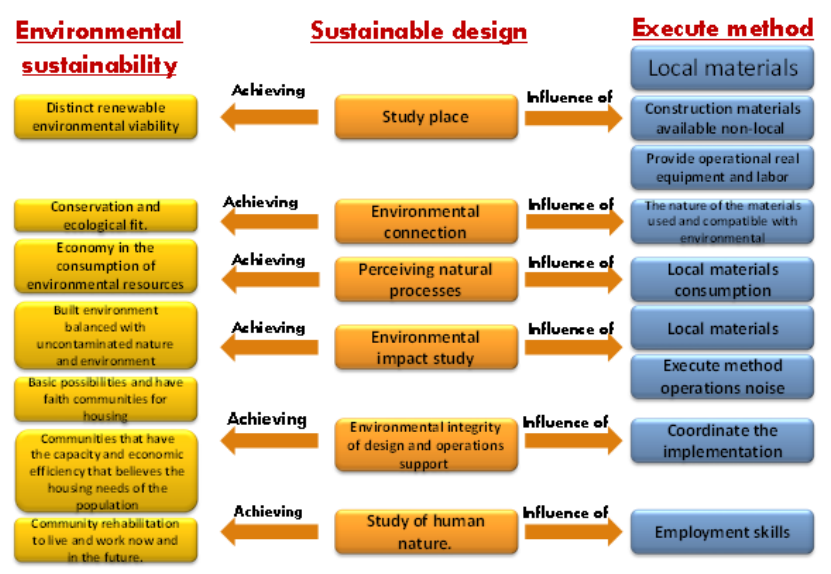

Fig. 2. Run harmonic reciprocal approach on the study

\section{A. The research is sequenced as follows}

- A study and analysis of the decision support system stages to choose the architectural project construction system as a primary stage.
- A study of factors and limits fuming the sustainable development and confirming it in an activated developed way.

- A study of the harmony relation between the construction system and the sustainable development and the exchangeable effects between them.

- A comparison and ordering the construction system priorities' and sustainable development priorities'.

- Concluding a mechanism of choosing the best construction system in harmony with the sustainable development.

The "Adrar Amlal" hotel in "Gaafar oasis"at Siwa in Egypt is considered the best example of applying the mechanism of choosing the construction system in harmony with sustainable development, the Oasis is a distinguished site environmentally at Siwa, it is centralized around (the White mountain),the project criteria is there use of the old oasis method of construction again to build environmental houses of a new view using building technology by using building materials which are suitable for Siwa environment such as (Karsheef (salted masses)-clay-cured palm cores)

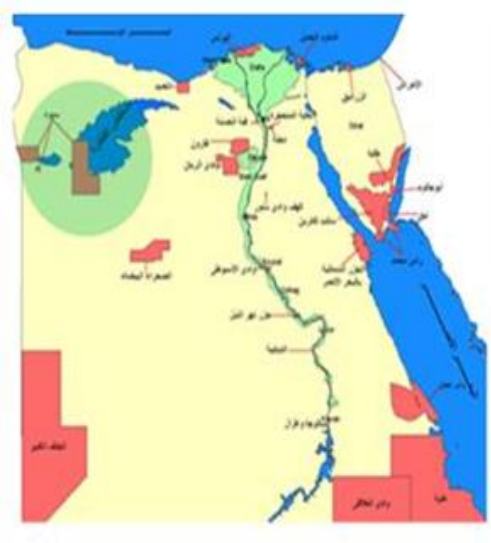

Fig .3. Siwa site for a map of natural reserves [11].

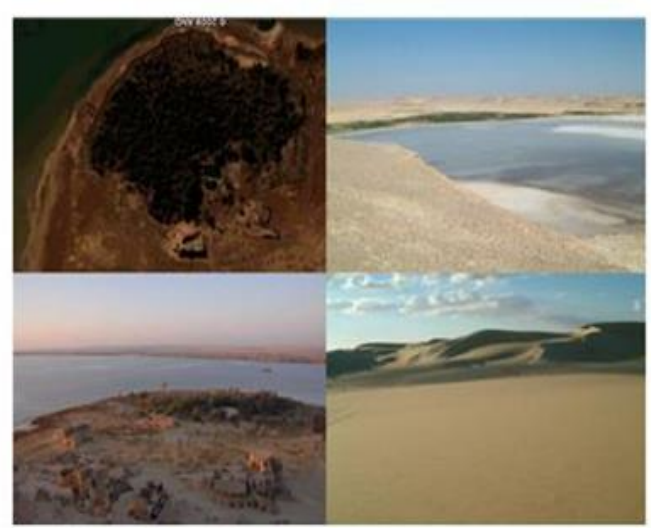

Fig.4.Natural determinants of the problem of site [12].

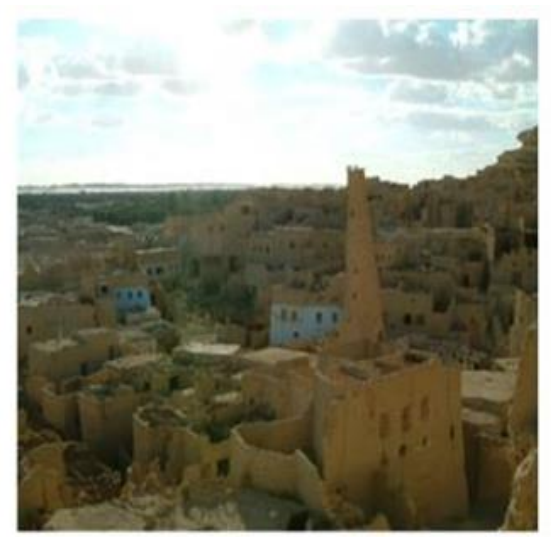

Fig.5.Architectural character of the Siwa Oasis [13].

\section{B. The research conclusions}

First: The choice of the best construction system suitable for the project environment is the first step to achieve sustainable development.

Second: The abundance of the environmental building materials is the most important factor to choose the environmental construction system.

Third: To make a relation between construction rates and "replacement and exchange "rates of projects in site to achieve the environmental sustainable development. 
Fourth: Studying and developing the traditional construction systems of projects in sustainable sites which helps to make the project more economic efficient and in harmony with environmental sustainability

Fifth: The architectural integration together with knowledge between different stages in study and construction helps to achieve the environmental sustainability for the built environment

\section{ANALYTICAL STUDY TO ADVANCED PROJECT (TENTH OF RAMADAN CITY)}

This part has concentrated on the neighborhood sustainability evaluation and its efficiency in improving the decision-making for sustainable development, it plans to provide a better understanding of the sustainability assessment at the neighborhood level and provide a critical analysis of both the theory and practice of neighborhood sustainability evaluation.

This project aim to introduce a case study for new application of the microclimate of urban open spaces is affected by several factors such as the urban form and geometry, urban density, the vegetation, the water levels and the properties of surfaces. Both climatic and physical factors are combined in order to attain sustainable human thermal comfort conditions.

\section{A. MATERIALS \& METHOD}

To design the form of a village, town or city, we should understand the outline design principles of the urban form.

- The concept of sustainability in urban design to residential communities and housing.

\begin{tabular}{ll|}
\hline \multicolumn{2}{l|}{ Several design concepts related to } \\
sustainable urban forms \\
1. Compactness \\
2. Sustainable transport \\
3. Density \\
4. Mixed land uses \\
5. Diversity \\
6. Passive solar design \\
7. Greening. \\
\hline
\end{tabular}

\begin{tabular}{|ll|}
\hline Principles sustainable neighborhood \\
1. & \multicolumn{1}{c|}{ planning: } \\
& an efficient street network \\
2. & High density \\
3. & Mixed land-use \\
4. & Social mix. \\
5. & Limited land-use \\
& specialization. \\
\hline
\end{tabular}

\section{- Urban Microclimate}

The main purpose of climatic design, on a macro (Settlement) and micro (building) scale, is to reduce uncomfortable conditions created by an excess of heat and dryness. Buildings must be adapted to extreme summer and Winter, day and night conditions to achieve a well-balanced indoor climate. Not only cooling is required; passive heating may also be required in winter and during cold nights. Protection is required from the intense radiation from the sun, ground and surrounding buildings, from dust, sandstorms and insects (flies). Glare has to be reduced and dust penetration prevented. Settlements and buildings, therefore, have to be compact, providing shade and controllable ventilation.

The urban microclimate plays an important role in building energy consumption and thermal comfort in outdoor spaces. Nowadays, cities need to increase energy efficiency, reduce pollutant emissions and mitigate the evident lack of sustainability [14].

\section{- Human Comfort}

Thermal comfort is the most important factor that Human comfort depends on. Thermal comfort is affected by six major factors which can be classified into two categories: personal factors - because they are characteristics of the occupants and environmental factors - that are related to the conditions of the thermal environment. The former consisting of clothing level and metabolic rate, while the latter is mean radiant temperature, air temperature, air speed and humidity. Even if all of these factors may change with time, standards usually refer to a steady state to study thermal comfort, just allowing a change in temperature by small scale. Air temperature is also governed by solar radiation.

\section{B. URBAN DESIGN IMPROVEMENT METHODS FOR THERMAL COMFORT}

There are a lot of urban microclimate moderation approaches Parameters like air temperature, relative humidity, mean radiant temperature, and wind velocity can be modified by the effect of urban interventions, which may improve the outdoor thermal comfort conditions [15].

- Cool Reflective Materials

- Water Surfaces

- Green Spaces and Vegetation

- Building Arrangements with Wind Movement 


\section{SIMULATION TOOLS IN URBAN DESIGN DECISIONS}

There are a Few studies have indicated that a good neighborhood Sustainability Assessment Frameworks and Tools should have the following characteristics Sustainability coverageconsideration of the major themes of sustainability of neighborhoods based on which their performance to be measured in a comprehensive and integrated way [16].

Several simulation tools related to urban design such as Ecotect, Urbanism, GIS, Envi-met and others. Each simulation tool deals with a specific area for instance. Urbanism is concerned with transportation, environmental planning, and metropolitan land use; While Envi-met is concerned with surface-plant-air interaction inside urban environments. All simulation tools have an unlimited number of points from the model that can be analyzed, whereas, in a measurement study, only the results derived from the measured spots are reliable.

On the other hand ECOTECT software is designed to improve the analysis, simulation, and optimization of high- performance buildings and systems. By using this software architects and engineers can test, evaluate and respond to a variety of strategies because it has a special use in the design and delivery of sustainable 'green' projects. 3D spatial models are one of the most advantages of the design and performance analysis tools because of the property of cutting edge that helps users to visualize simulation output, smoothing the translation of simulation results into the project design. Using simulation software, design professionals are able to continuously study and predict how decisions will impact the performance of the building from the early phases of design through occupancy without significant investment in mockups or manual calculations. Simulation tools such as ECOTECT and other similar software can improve the building industry by giving architects and engineers the power to use performance-based criteria in the design of projects.
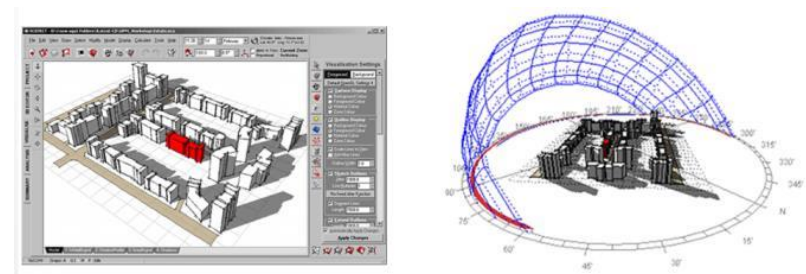

Fig. 6. ECOTECT (Building Performance Simulation Software)

(http://www.zigersnead.com/current/blog/post/ecotect-buildingperformance-simulation-software)

\section{Tenth of Ramadan City (case study)}

El Asher City or Tenth of Ramadan City is located in the Sharqia governorate of Egypt close to the city of Cairo and follows the Urban Communities Authority. It is one of the first generation cities in Egypt, and also one of the largest new industrial cities. It was constructed to provide job opportunities for youths as well as to attract the population increase to the outside of Cairo and the narrow valley, its climate classified as hot desert as the rest of Egypt.

1. Design Concept of the project

Design Concept of project (Figure 7) based on meeting the determinants architectural device "EI Asher City or Tenth of Ramadan City" functional requirements in line with the Principles sustainable neighborhood planning to (Figures 8, 9):

- Achieve the functional requirements of the project according to the structural and architectural determinants.

- Reduce waste entrances of apartment buildings in the movement areas (roads) role habitation and what reduces the cost of the housing unit.

- Designed Muscat approved symmetric to afflict balance in marketing and reduce differences to distinguish between the blanks in order to achieve special layers housing average and exterior distribution quality takes into account the nontypical after the concept of housing People's abhorrent to rush to

- The Building was used major traffic battery different their positions to ensure optimal routing and compatibility with the gradient vacuum spaces planning (Figures 10, 11). 
- The idea of assembling buildings to reduce the blanks rely on among themselves to provide spaces of the inner shadows.

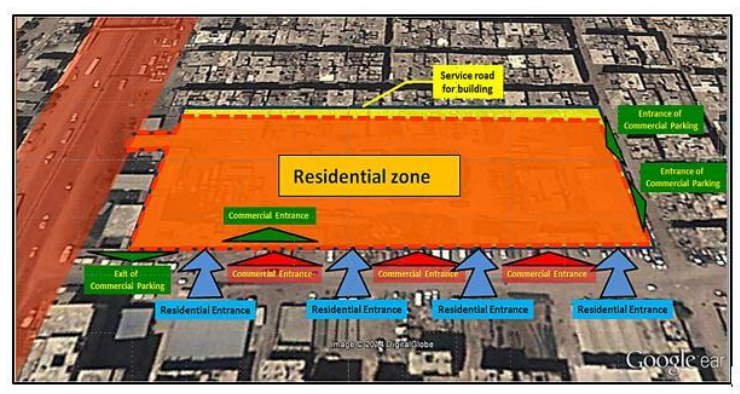

Fig. 7. Design Concept of the project

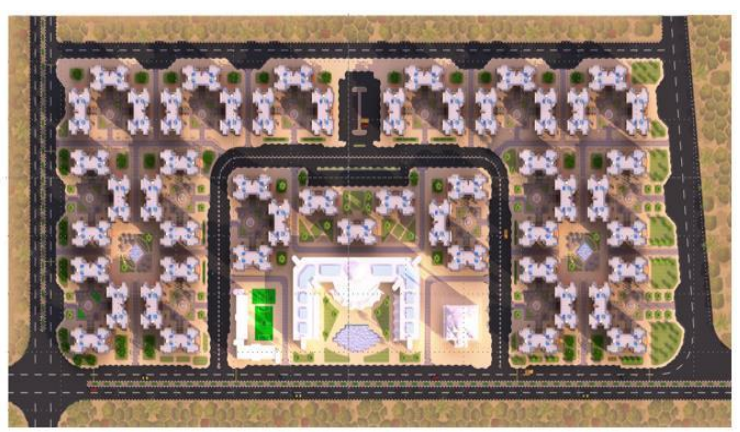

Fig. 8. Residential Neighborhood Layout

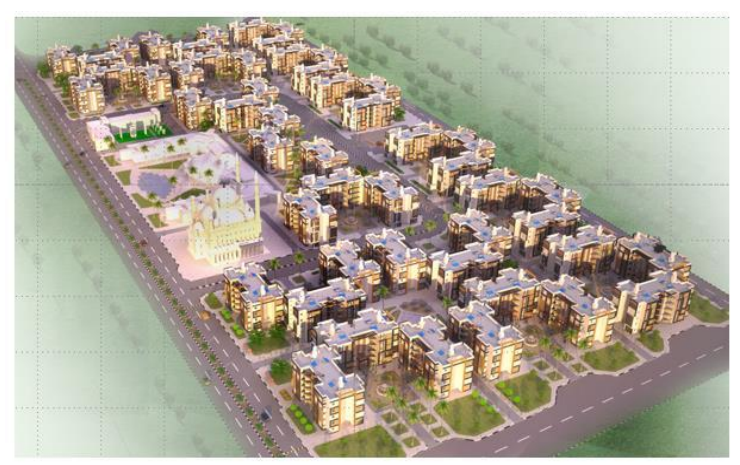

Fig. 9. Site Perspective

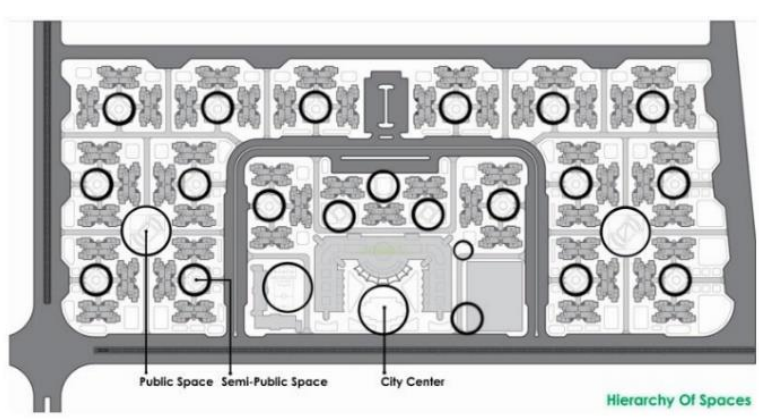

Fig. 10. Hierarchy of Spaces
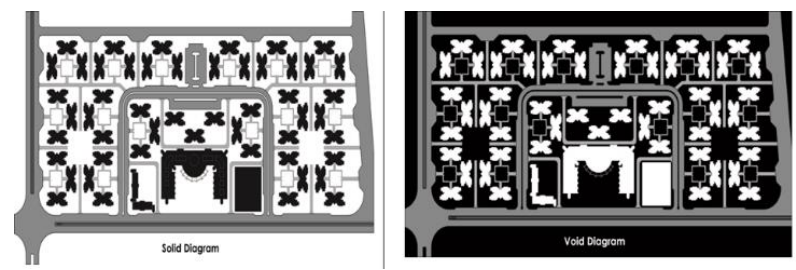

Fig. 11. Solid and Void Diagram

E. Case study evaluation

The simulation was run on Neighboring residential in Tenth of Ramadan City In order to investigate the local microclimate (Solar Radiation, air temperature, Relative humidity) in the climate of Egypt, Egypt as a proposed area. Readings of the Microclimatic parameters were run consecutively currently, expected and proposed then compared on each indicator.(Figures 12, 13, 14 and 15).
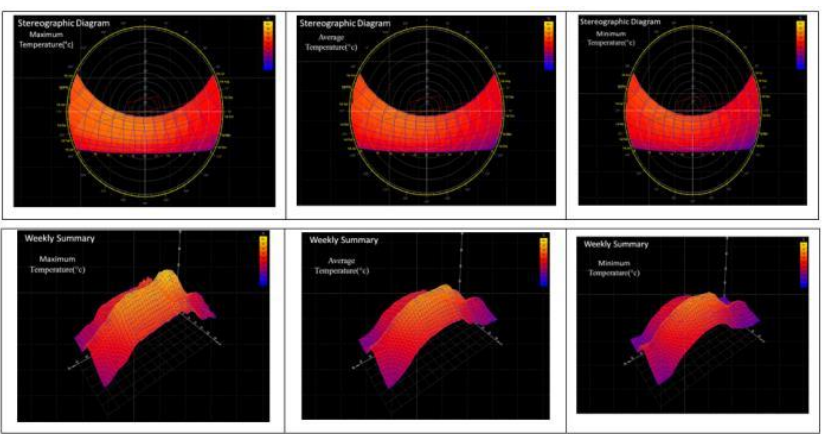

Fig. 12. The Stereographic Diagrams represent the range of Maximum Temperature in between $(40-45){ }^{\circ} \mathrm{C}$ on June and observed that the highest day temperature is on 7 July.
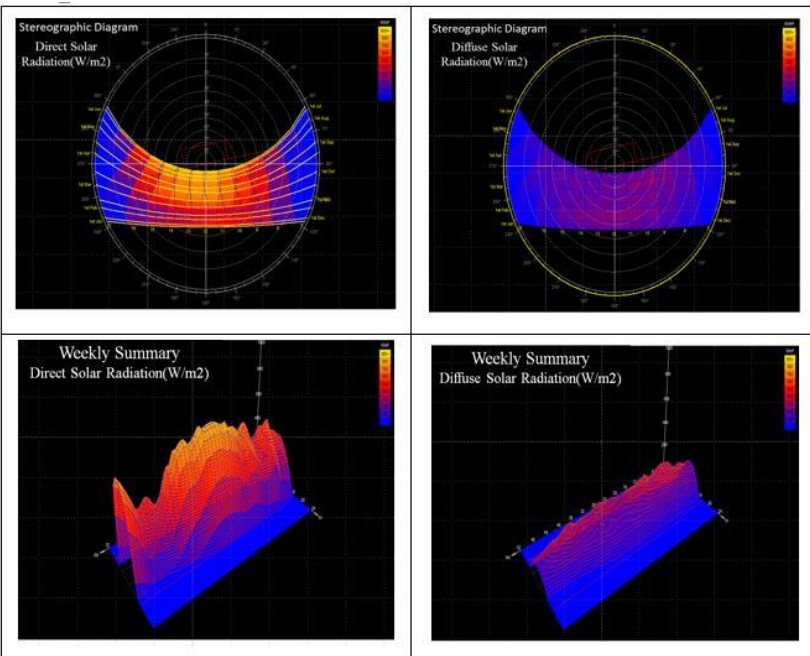

Fig .13. The Stereographic Diagrams represent the Direct Solar Radiation (W/m2) \& Diffuse Solar Radiation (W/m2). 


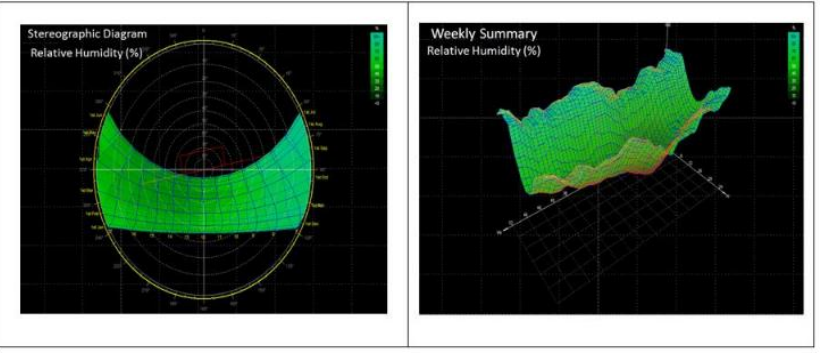

Fig .14. the Stereographic Diagrams represent the Relative Humidity.

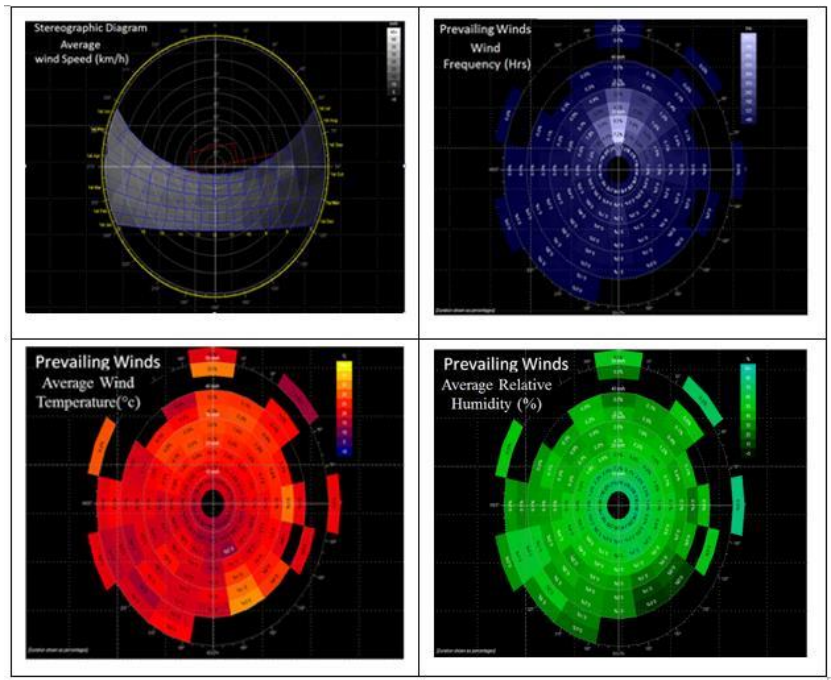

Fig .15. The Stereographic Diagrams represent the Prevailing Winds.

VIII. CONCLUSION

This paper presents a review on urban sustainability with the aim of Understanding key technical principles to be considered while planning for new neighborhoods. Sustainable neighborhoods evolution and initiatives are described, several design concepts related to sustainable urban forms are defined and their sustainability characteristics investigated. (Focusing on sustainability concepts under the triple bottom line of environmental, economic, and social dimensions) and practitioners.

Rapid urbanization has brought environmentally, socially, and economically great challenges to cities and societies. To build a sustainable neighborhood, these challenges need to be faced efficiently and successfully. In this regard, the first step of action is to determine the sustainability levels of neighborhoods. From this perspective, the literature points to a number of NSA tools. However, as the critique of these tools suggests they have limitations in their indicator systems and adaptation in the developing country context is challenging.

There are many approaches that aim to achieve sustainable urban forms. Different approaches use different scales

of concepts, as well as emphasizing some concepts over others. In practice, many local governments, planning consultants, landscape architects, and so on are grappling much more specifically with aspects of sustainable urban form through a variety of planning and design approaches and policies.

Different urban forms give differently to sustainability. Moreover, different planners and scholars may develop different combinations of design concepts to achieve sustainable development goals. They might come with different forms, where each form emphasizes different concepts. However, all should be forms that environmentally contribute beneficially to the planet for the present and future generations.

The ideal sustainable urban form according to the design concepts of sustainable urban form is that which has a high density and adequate diversity, compact with mixed land uses, and its design is based on sustainable transportation, greening, and passive solar energy. Ultimately, sustainable urban forms aim to achieve different objectives. The most prominent among them are decreased energy use, reduced waste and pollution, reduced automobile use, preservation of open space and sensitive ecosystems, and livable and community-oriented human environments.

The Five Principles are highly interrelated and support each other. High density provides the population and activity basis for a sustainable neighborhood; adequate street density is the material basis; mixed land-use and social mix shape the land use and social life in the neighborhood, and limited land use specialization is the first step towards mixed neighborhoods.

The Five Principles balance population growth, economic growth, rapid urbanization, sustainable urban development and other factors, and try to establish a new urban system. In this system, population and urban infrastructure accomplish economies of scale; diversified social networks and the diversity of land uses to support each other and develop together and urban space and urban dwellers live and develop in harmony. 
Besides good planning and design decisions, the application of these principles also requires supporting legal frameworks, an analysis of the local society and economy, appropriate infrastructure technology and capacity, and the institutional capacity to enforce decisions.

\section{REFERENCES}

[1] Mohammadjavad, M., Arash, Z., Airya, N., Setareh, G., Narjes, E., 2014 "Dilemma of green and pseudo green architecture based on LEED norms in case of developing countries" International Journal of Sustainable Built Environment (2014) 3, 235-246.

[2] Thomas Rettenwender, 2009, M.A., Mag. Arch., LEED AP, Architect and Niklas SpitzMonterey Peninsula College INTD62 Spring 2009"The Principles of Green Building Design" Spring 2009.

[3] Roy Madhumita, 2008, Dept. Of architecture, Jadavpur university, Kolkata, India, "Importance of green architecture today".

[4] "Burcu, G., 2015, "Sustainability Education by Sustainable School Design" Dokuz Eylul University, Department of Architecture, Turkey Procedia - Social and Behavioral Sciences 186 (2015) $868-873$.

[5] USGBC, 2002, U.S. Green Building Council, Building Momentum: "National Trends and Prospects for High-Performance Green Buildings," Prepared for the U.S. Senate Subcommittee on Environmental and Public Works by the U.S. Green Building Council, November 2002.

[6] CBFEE, 1999, "Skylighting and Retail Sales: An Investigation into the Relationship Between Daylighting and Human Performance," The Heschong Mahone Group, on behalf of the California Board for Energy Efficiency Third Party Program, 1999.
[7] CGB, 2009, Center for Green Building, "Building the GREEN Garden State", New Jersey Municipalities magazine. Vol. 86, No. 6, June 2009.

[8] Kats, Gregory H.2006, "Greening America's Schools Costs and Benefits," Capital E.

[9] Kats, Gregory H. 2003, "Green Building Costs and Financial Benefits." Massachusetts Technology Collaborative.

[10] Woolley T. 2006. "Natural Building: A Guide to Materials and Techniques". Crowood Press.

الادارة المركزية للمحميات الطبيعية(2002) "اعلان 2002 محمية [11] سيوة الطبيعية بمحافظة مطروح " ,القاهرة ,مصر

فريد, عماد (2008) "البناء التقليدى فى مصر وحكاية الحو ائط الحاملة [12]

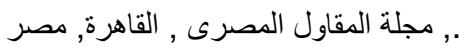

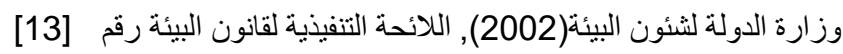
338 الصادر سنة 1995, القادة التفرة , مصر البئة رفر

[14] Ragheb G., El-Shimy H. and Ragheb A., 2015; "LAND FOR POOR: TOWARDS SUSTAINABLE MASTER PLAN FOR SENSITIVE REDEVELOPMENT OF SLUMS", ISSN 18770428, Social and Behavioral Science, Part 1, 212-228.

[15] El-Darwish I.; Ragheb A and Ahmed Sh., 2015 "THE ROLE OF SIMULATION IN URBAN DESIGN DECISIONS: MICROCLIMATE AND HUMAN COMFORT CONSIDERATIONS IN PLANNING", ISSN 2079-4096, Architecture and Planning Journal - Faculty of Architecture Engineering (BAU).

[16] Yigitcanlar, T., Kamruzzaman , Md., and Teriman, S., (2015), "Neighbourhood Sustainability Assessment: Evaluating Residential Development Sustainability in a Developing Country Context" Sustainability, 7, 2570-2602; doi:10.3390/su7032570. 